\title{
L'Érotique balzacienne, textes réunis et présentés par Lucienne Frappier-Mazur et Jean-Marie Roulin
}

\section{Philippe Andrès}

\section{(2) OpenEdition}

\section{Journals}

Édition électronique

URL : http://journals.openedition.org/studifrancesi/36372

DOI : 10.4000/studifrancesi.36372

ISSN : 2427-5856

Éditeur

Rosenberg \& Sellier

\section{Édition imprimée}

Date de publication : 1 juillet 2005

Pagination : 182-183

ISSN : 0039-2944

\section{Référence électronique}

Philippe Andrès, «L'Érotique balzacienne, textes réunis et présentés par Lucienne Frappier-Mazur et Jean-Marie Roulin », Studi Francesi [En ligne], 145 (XLIX | I) | 2005, mis en ligne le 30 novembre 2015, consulté le 20 avril 2021. URL : http://journals.openedition.org/studifrancesi/36372 ; DOI : https:// doi.org/10.4000/studifrancesi.36372

Ce document a été généré automatiquement le 20 avril 2021.

\section{(c) $($ ) $\odot$ (8)}

Studi Francesi è distribuita con Licenza Creative Commons Attribuzione - Non commerciale - Non opere derivate 4.0 Internazionale. 


\title{
L'Érotique balzacienne, textes réunis et présentés par Lucienne Frappier- Mazur et Jean-Marie Roulin
}

\author{
Philippe Andrès
}

\section{RÉFÉRENCE}

AV. VV. L'Érotique balzacienne, textes réunis et présentés par LUCIENNE FRAPPIER-MAZUR et JEAN-MARIE ROULIN, Paris, SEDES, 2001 («Groupe international de recherches balzaciennes, Collection du Bicentenaire»), pp. 192.

1 Les études qui forment les cinq parties de cet ouvrage collectif ont pour objectif d'éclairer l'érotique balzacienne comprise comme dynamique d'une machine désirante. L'ensemble, particulièrement équilibré, s'appuie sur une approche à orientation psychanalytique.

2 Il s'agit tout d'abord d'«énoncer le désir». Les quatre analyses de cette première partie approfondissent le non-dit balzacien par une micro-analyse du Lys de la vallée et de la dialectique entre multiple et (Janet BEIZIER, pp. 11-22); par la mise à nu du fonctionnement $\mathrm{du}$ "paradigme érotique» grâce au truchement de l'euphémisme et de la métaphore (Éric BORDAS, pp. 23-34); par l'étude du motif floral dans Honorine (Pierre LAFORGUE, pp. 35-40) et la lecture des quatre premières années de la correspondance entre Balzac et Madame Hanska où la haine semble être un moteur particulièrement efficace.

La deuxième partie consacrée aux «Figures du fantasme» s'intéresse au concept de «fantaisie» au sens freudien du terme. Anne-Marie BARON (pp. 51-58) souligne cette omniprésence fantasmatique dans «Le Succube, condensé de fantasmes». La coquette et le dandy forment deux types de personnages narcissiques symétriques pour Deborah HOUK SCHOCKET (pp. 59-66). André LORANT (pp. 67-74), quant à lui, s'intéresse à Clotilde de Lusignan, roman de jeunesse de Balzac. 
4 La partie «Voir et savoir» cerne la possession du corps féminin par le regard. La brillante analyse de Catherine NESCI (pp. 75-86) inscrit ce regard désirant dans la modernité de l'espace urbain. Peter BROOKs (pp. 97-104), quant à lui, se fait le défenseur, à contre-courant, de la théorie dans l'oeuvre de Balzac. Maurice SAMUELs (pp. 105-116) élargit sa problématique en l'englobant dans une image fantasmée collective, celle du grand homme napoléonien.

5 S’agissant des «Économies du désir: dépense et manque, profits et pertes» - partie la plus importante de l'ouvrage, il revient aux cinq études littéraires de souligner les transfonnations de l'énergie sexuelle sous la triple fonne de la passion, de la sublimation ou du refoulement. L'analyse de Philippe BERTHIER (pp. 157-170) sur les Mémoires de deux jeunes mariées qui clôt ce chapitre s'interroge sur la pertinence de la dédicace de ce texte à George Sand et démontre qu'Éros et Agapè ne s'articulent pas forcément dans un «affrontement monolithique».

6 La dernière partie, réduite à deux études, concerne «L'érotique balzacienne, du roman au cinéma». Il s'agit de voir comment le passage du narratif au visuel a pu transposer la dimension érotique du texte balzacien. Sandy PETREY (pp. 171-180) compare Une Passion dans le désert et le film de Lavinia Currier, Passion in the Desert (1998). Gérard GENGEMBRE (pp. 181-186), en s'intéressant au Vautrin de Pierre Billon ou à La Belle Noiseuse de Jacques Rivette, suggère des pistes de recherches concernant la relation de peintre à modèle et entre metteur en scène et acteur.

7 Finalement, l'ensemble des études de cet ouvrage collectif permet au lecteur de s'interroger sur la nature du moteur énergétique de la création romanesque balzacienne. L'approche psychanalytique, unitaire dans ce volume, fonctionne ici comme la méthode privilégiée pour tenter de comprendre les processus encore mystérieux de l'acte créateur. 